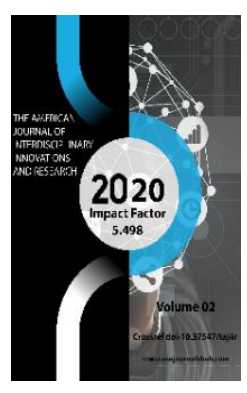

\title{
The Role Of Physical Exercises In The Development Of Consciousness
}

\author{
Dilmurodov Doston Bakhshullaevich \\ Student Of Uzbek State University Of Physical Culture And Sport, Uzbekistan
}

Copyright: Original content from this work may be used under the terms of the creative commons attributes 4.0 licence.

\section{ABSTRACT}

This article deals with the importance of exercise in the development of consciousness. Here, in the examples, one can see the positive effects of exercise on human health, on performance and life. The article will be useful to all interested readers.

\section{KEYWORDS}

Physical exercise, health, movement, thinking, physical labor, activity, mind.

\section{INTRODUCTION}

Exercise improves their ability to think, plan, and their math skills. Exercise is associated with increased activity in the areas of the brain that are responsible for integrated thinking and self-control. In physically active people, the so-called area of the executive brain functions associated with planning, logic, abstract thinking and social behavior increases, and your mind will also be awake.

Today it is impossible to find a single sphere of human activity that is not related to physical culture, since physical culture and sports are generally recognized material and spiritual values of society as a whole and of each person individually. 
Historically, physical culture has developed primarily under the influence of the practical needs of society in the full-fledged physical preparation of the younger generation and the adult population for work. At the same time, as the systems of education and upbringing were developing, physical culture became the basic factor in the formation of motor skills and abilities. A qualitatively new stage of understanding the essence of physical culture is associated with its influence on the spiritual sphere of a person as an effective means of intellectual, moral, aesthetic education.[1]

Unfortunately, many people do not follow the simplest, science-based norms of a healthy lifestyle. Some become victims of inactivity (hypodynamia), which causes premature aging, others go overboard in food with the development of obesity, vascular sclerosis, and in some cases, diabetes mellitus, which is almost inevitable in these cases, while others do not know how to rest, be distracted from work and domestic concerns, are always restless, nervous, suffer from insomnia, which ultimately leads to numerous diseases of the internal organs. Some people, surrendering to the addiction to smoking and alcohol, actively shorten their lives.

\section{MATERIALS AND METHODS}

A person satisfied the natural need for movement throughout his life in the labor process. With the development of scientific and technological progress, the living conditions of people began to change. A characteristic feature of these changes was the steady reduction in the share of physical effort in work and life. Such specialties as diggers, hammer-cutters, lumberjacks, blacksmiths began to disappear, and their functions were transferred to combines, automatic machines, robots. Workers began to transform themselves into automatic line operators. In the field of production and science, computers are increasingly used. Over a short historical period in the last 60-70 years, the share of muscle labor in the sphere of material production has decreased by almost 200 times.[1]

The living conditions, which previously required significant expenditures of physical labor, have also changed. Vacuum cleaners, floor polishers, washing machines appeared that freed people from physical exertion. Economists have calculated that there are, on average, about 100 different technical devices for every inhabitant of the Earth, the overwhelming majority of which facilitate or replace physical labor.

The process of urbanization of the population has significantly intensified. The growth of large cities led to the development of urban transport, elevators, telephones, television, which contributed to a decrease in the physical activity of people.[2]

As a rule, a person after work, having got home in public transport, spends the rest of the time reading or watching $T V$. The researcher found that the increasing number of obese schoolchildren is due to the fact that these boys and girls spend several times more time watching TV than their rural peers. Statistics also show that pathological changes in the circulatory system, respiratory tract and nervous system in cities are one and a half to two times higher than in rural areas.[6]

Thus, scientific and technological progress, along with the improvement of living and 
working conditions in a modern society, creates the preconditions for a sedentary lifestyle. Restriction of the function of movement causes a special condition hypokinesic syndrome or illness. Physical inactivity (or hypokinesia), like rust, corrodes professional performance, worsens health, and shortens life expectancy. Lack of movement is the onset of diseases, the leading place among which is cardiovascular pathology: hypertension, atherosclerosis, ischemia, heart attacks, etc.

The essence of the influence of movements on the body is as follows. Movements, even relatively simple ones, are carried out with the participation of a large number of muscles (for example, about 90 muscles are involved in the act of breathing). The work of some muscles is aimed at ensuring the main motor act (purposeful action), the contraction of others helps to ensure that the movement is coordinated, the activity of the third muscle group creates the most favorable body posture for this movement by distributing muscle tone.

Locomotor activity is a process in which not only muscles are involved, but also many parts of the nervous system from peripheral nerves to the higher centers of the cerebral cortex. Signals appear in the working muscles that have a stimulating effect on the central nervous system, supporting the performance of the nerve centers. The systematic flow of such signals has a positive effect on the development and functions of the brain, the state of the autonomic nervous system.

Sensory organs - analyzers take part in the organization of movement as an apparatus of control and information. The cardiovascular, respiratory, endocrine systems, digestive organs, excretions, etc. are involved in providing movements with everything necessary. The more varied the motor activity, the more perfect the structure of the body, the higher the level of functional capabilities, and longer life. For example, the lifespan of different species of animals, approximately the same in size and weight, depends on the lifestyle: the rabbit lives on average 5 years, the hare - 15; mouse - 2 years, bat - up to 30; cow 20-25, horse - 40-50. Life expectancy is proportional to the degree of physical activity.[2]

For the normal functioning of the brain, it is necessary that impulses from various systems of the body come to it, the mass of which is almost half of the muscles. Muscle work creates a huge number of nerve impulses that enrich the brain with a stream of influences that keep it in working order. When a person performs mental work, the electrical activity of the muscles increases, reflecting the tension of the skeletal muscles. The higher the mental load and the stronger the mental fatigue, the more pronounced generalized muscle tension. The connection of movements with mental activity is characterized by the following patterns.

During intense mental work, people have a concentrated facial expression, pursed lips, and this is all the more noticeable, the stronger the emotions and the more difficult the task that has to be solved. When trying to assimilate any given material, a person unconsciously contracts and strains the muscles that flex and straighten the knee joint. This happens because the impulses coming from tense muscles in the central nervous system stimulate the activity of the brain, helping it 
maintain the desired tone. Activities that do not require physical effort and precisely coordinated movements are most often accompanied by tension in the muscles of the neck and shoulder girdle, as well as the muscles of the face and speech apparatus, since their activity is closely related to the nerve centers that control attention, emotions, and speech. If a person writes quickly and for a long time, the tension gradually moves from the fingers to the muscles of the shoulder and shoulder girdle. By this, the nervous system seeks to activate the cerebral cortex and maintain efficiency. Prolonged work becomes addictive to these stimuli, the process of inhibition begins, performance decreases, since the cerebral cortex is no longer able to cope with nervous excitement and it spreads throughout the muscles. It is possible to extinguish it, to release muscles from excessive tension with the help of active movements, physical exercises.

\section{RESULTS AND DISCUSSIONS}

The tone of the nervous system and the performance of the brain can be maintained for a long time if the contraction and tension of various muscle groups rhythmically alternate with their subsequent stretching and relaxation. This mode of movement is typical for walking, running, skiing, skating, etc. Successful mental work requires not only a trained brain, but also a trained body, muscles that help the nervous system to cope with intellectual stress.[5]

Stability and activity of memory, attention, perception, information processing are directly proportional to the level of physical fitness. Various mental functions largely depend on certain physical qualities - the strength of speed, endurance, etc. Therefore, properly organized physical activity and optimal physical activity before, during and after the end of mental work can directly affect the preservation and increase of mental performance.

Normal vital activity of the body is possible only with a certain organization of various muscular loads, which are constantly necessary for human health. It is a combination of a variety of motor actions performed in everyday life, movements, organized and independent physical culture, sports and the term "physical activity". [3]

It is the level of physical activity during the holidays that reflects the natural need of young people for movement.

The specific part of physical education contains the solution of motional problems: the formation of physical qualities, abilities and skills of motion control, as well as the possibilities of rational use of physical potential.

It is possible to show the influence of physical exercises on the mental development of children with the normal development of the child's body. If you think that it is possible to choose exercises only for training brain activity, then you are deeply mistaken. This has long been proven by science.

Exercise has an indirect, but irreplaceable, positive impact on a child's successful intellectual development. Stimulating the development of the child's body towards the logical mind at first (initial school years) can bring an advantage over peers in this area, but over time this advantage will decrease due to the poorly developed physical body.[3] 
The main feature of the human body is that it grows and develops, and these processes can only take place successfully with regular physical activity. The optimal routine of physical activity should consist of morning exercises, outdoor games and activities, as well as light physical activity in the evening.

The lack of the necessary minimum of movements indirectly has a very negative effect on mental development. This is expressed in such tendencies: breathing becomes shallow, the metabolic rate in the body decreases, blood stagnation in the legs is observed, which leads to a decrease in attention, weakening of memory, and a decrease in the speed of mental operations.

Physical activity will contribute not only to the development of a healthy body:

- An active lifestyle enhances capillary blood circulation, which contributes to the flow of nutrients to all organs and systems of a person. The brain is no exception, active blood circulation enhances brain activity.

- The brain receives nerve signals from receptors located throughout the body. Exercise increases the flow of nerve impulses to different parts of the brain, which helps it develop harmoniously.

- For the successful functioning of the brain, nutrients are needed, which can only be obtained through the digestive system, which works much more efficiently after light physical activity. Improves appetite, liver and kidney function.

Exercise is undoubtedly very beneficial for mental development.

The use of physical exercise as a means of active recreation.
Distinguish between passive and active rest, associated with motor activity. Physiological examination of active rest is associated with the name of I.M. Sechenov, who for the first time showed that changing the work of some muscles by the work of others better contributes to the restoration of strength than complete inaction.

This principle became the basis for the organization of recreation in the field of mental activity, where appropriately selected physical activity before the start of mental work, during and after it has a high effect in maintaining and increasing mental performance. [4]

No less effective are daily independent physical exercises in the general mode of life. In the process of their implementation, a "dominant of movement" appears in the cerebral cortex, which has a beneficial effect on the state of the respiratory and cardiovascular systems, activates the sensorimotor zone of the cortex, and raises the tone of the whole organism. During active recreation, this dominant contributes to the active course of recovery processes.

An active lifestyle enhances capillary blood circulation, which contributes to the flow of nutrients to all human organs and systems. The brain is no exception, active blood circulation enhances brain activity.

Nerve signals from receptors located throughout the body enter the human brain. Exercise increases the flow of nerve impulses to different parts of the brain, which helps it develop harmoniously.

Morning hygienic gymnastics is the least difficult, but quite effective form for accelerated inclusion in the working day. It 
speeds up bringing the body to a working state, increases the flow of blood and lymph in all parts of the body and speeds up breathing, which activates metabolism and quickly removes decay products that have accumulated overnight. Systematic exercise improves blood circulation, strengthens the cardiovascular, nervous and respiratory systems, improves the activity of the digestive organs, promotes more productive activity of the cerebral cortex. [4]

Daily morning exercises, supplemented by water procedures, are an effective means of increasing physical fitness, fostering will and hardening the body.

Dynamic exercises such as jogging, skiing, cycling, swimming involve a large amount of mechanical work that requires significant energy consumption. Physical activity intensifies metabolism and significantly increases blood circulation.

When performing muscular work, the heart is forced to throw out many times more blood into the vascular system than in a calm state. The pressure in the central blood vessels increases, which greatly increases the speed of blood flow throughout the body.

The work of scientists in recent years has shown that during physical activity, the intensity of blood circulation in the muscles increases several times, and in the brain - only by a few percent.

In a healthy body, the risk of overfilling the brain with blood is excluded. This is facilitated by a reliable defense system that passes to the nerve cells as much blood as is necessary for their normal functioning.

Thus, the effect of intense physical work on the brain is manifested in the activation of the functions of the corresponding defense systems, which is the most important condition for training them and increasing their efficiency. The special value of dynamic exercises such as running, skiing, backpacking, etc. lies in their diversity. They contribute to the expansion of the range of actions of the protective and adaptive apparatus of the brain.

\section{CONCLUSION}

So, physical culture is presented as the most important basic component of the formation of the general culture of a person.

1. Regular physical education and sports are the universal means that can help everyone resist the tense rhythm of life, neuropsychic overload, including mental work.

2. Even simple techniques of self-control before starting regular physical education and sports can reveal the degree of adaptation of the body to physical activity.

3. The concept of the nature of health is a continuum, where at one pole is the point of view that health is the absence of diseases, the ideal state of well-being, the property of people that can be used without caring about it at all; on the other health as a sustained balance, as a "tool for use in the environment in which we live". 


\section{EFFECTS OF TRAINING ON THE BRAIN}

\begin{tabular}{|c|l|}
\hline Exercise bike & the best tool against stress \\
\hline Running & $\begin{array}{l}\text { relieves depression, helps to overcome laziness, overcomes } \\
\text { fatigue }\end{array}$ \\
\hline Cardio exercise & enhances a passion for reading and learning. \\
\hline Heavy exercise & helps to focus \\
\hline Aerobic exercise & $\begin{array}{l}\text { increases the ability to acquire knowledge and has a positive } \\
\text { effect on increasing self-esteem }\end{array}$ \\
\hline $\begin{array}{c}\text { Swim in the morning } \\
\text { and in the evening }\end{array}$ & $\begin{array}{l}\text { gives cleanliness and lightness, evening swimming } \\
\text { strengthens nerve fibers }\end{array}$ \\
\hline Regular exercise & helps to get rid of insomnia \\
\hline Every physical exercise & produces the hormone of happiness in our body \\
\hline
\end{tabular}

\section{REFERENCES}

1. Kagan V.E. Internal health picture - a term or a concept? // Questions of psychology. 1993. No. 1. S. 86-88.

2. Razumov A., Ponomarenko V., Piskunov V. Health of a healthy person. Fundamentals of Restorative Medicine. M .: Medicine. 1996.

3. Romanenko V.A. Human motor abilities. Donetsk: UK Center, 1999.

4. Sieres D., Gavidia V. On various approaches to the concept of "health" // School of health. 1998. Vol.5 No. 1. S. 7-16.

5. Population health statistics, statistical analysis of key indicators: http://works.tarefer.ru/75/100004/index.ht $\mathrm{ml}$

6. https://www.klerk.ru/boss/articles/266924

7. Atoeva M.F. Frequency of teaching physics. Postgraduate student and applicant. Moscow, 2010. - No. 6. - S. 41-43.

8. Atoeva MF Electrodynamics of by̆limini davrilik tizimi asosida tashkil etish. Нalk ta'limi. - Toshkent, 2012. - No. 1. -B. 52-54.
9. Atoeva M.F. Uzluksiz physicist talim samaradorligi. Uzluksiz talim. - Toshkent, 2012. - No. 3. - B. 19-23.

10. M.F. Atoyeva. Interdisciplinary relations in physics course at specialized secondary education. The Way of Science. Volgograd, 2016. - №9 (31). - P.22-24.

11. M.F. Atoyeva. The significance of periodicity at teaching physics. The Way of Science. Volgograd, 2016. - № 10 (32). - P.62-64.

12. Atoeva M.F. The effectiveness of teaching electrodynamics based on the technology of periodicity. The Way of Science. Volgograd, 2016. - No. 10 (32). - P.65-66.

13. M.F. Atoyeva. Use of Periodicity in Teaching Physics. Eastern European Scientific Journal. - Düsseldorf-Germany, 2017. № 4. P. 35-39.

14. M.F. Atoyeva. Didactic foundations of intermedia relations in the training of university students. International Scientific Journal. Theoretical \& Applied Science. p-ISSN: 23084944 (print) e-ISSN: 2409-0085 (online). Year: 2020 Issue: 06 Volume: 86, P. 124.

15. M.F. Atoyeva, R. Safarova. Pedagogical integration as a means of forming 
professionally important qualities among students of a medical university. Academicia. ISSN: 2249-7137 Vol. 10, Issue 8, August 2020. Impact Factor: SJIF $2020=7.13$ ACADEMICIA: An International Multidisciplinary Research Journal https://saarj.comэ.

16. M.F. Atoyeva. Pedagogical Tests As An Element Of Types of Pedagogical Technologies. The American Journal of Applied Sciences, 2(09), (TAJAS) SJIF-5.276 DOI-10.37547/tajas Volume 2 Issue 9, 19.09.2020. ISSN 2689-09. 92 The USA Journals, USA www.usajournalshub.com/index.php/tajas 164-169. Имп.5.2.

17. Farkhodovna, A. M. (2020). The problems of preparing students for the use of school physical experiment in the context of specialized education at secondary schools. European Journal of Research and Reflection in Educational Sciences, 8 (9), 164-167. 